\title{
AVALIAÇÃO DE PROGRAMAS DE EDUCAÇÃO AMBIENTAL VOLTADOS PARA GESTÃO DE RESÍDUOS SÓLIDOS EM ESCOLAS MUNICIPAIS DE PINHAIS/PR
}

\author{
Flavia Scupino ${ }^{1}$ \\ Tamara Simone van Kaick ${ }^{2}$
}

\begin{abstract}
Resumo
Este estudo tem por objetivo avaliar programas de Educação Ambiental voltados para gestão de resíduos sólidos em duas escolas municipais de Pinhais/PR. Os programas tratam da campanha Acabe com o Desperdício e do projeto Escola 100\% Reciclável, que, até então, não haviam sido submetidos a qualquer tipo de avaliação para identificação do alcance de suas metas. $\mathrm{O}$ estudo de caso foi desenvolvido nas Escolas Municipais Aroldo de Freitas e 31 de Março, junto aos alunos do $4^{\circ}$ e $5^{\circ}$ anos do ensino fundamental. O método qualiquantitativo foi utilizado na análise dos resultados obtidos por meio da aplicação de questionários survey, a fim de avaliar e investigar o conhecimento dos sujeitos da pesquisa a respeito dos programas citados. As respostas dos questionários foram agrupadas em categorias e, assim, puderam ser traduzidas em dados percentuais. Os resultados apontaram que as ações do projeto Escola $100 \%$ Reciclável apresentaram melhores resultados em relação à campanha Acabe com o Desperdício.

Palavras-chave: Escolas. Avaliação de Programas de Educação Ambiental. Resíduos Sólidos.

\section{ENVIRONMENTAL EDUCATION PROGRAM EVALUATION FOCUSED ON THE MANAGEMENT OF SOLID WASTES IN MUNICIPAL SCHOOLS IN PINHAIS/ PR}

\begin{abstract}
This study aims to evaluate environmental education programs for managing solid waste in municipal schools in Pinhais / PR. The programs are related to the campaign Stop the Waste and to the project $100 \%$ Recyclable School, which, until this moment, have not undergone any type of evaluation to assess the extent of its goals. The case study was developed in Municipal Schools, Aroldo de Freitas and 31 de Março, together with the students of 4th and 5th grades of Elementary School. The qualitative and quantitative method was used to analyze the results obtained through the application for applying survey questionnaires in the case study schools in order to evaluate and investigate the knowledge of the subjects regarding these programs. The survey responses were grouped into categories and thus could be translated into percentage data. The results of the questionnaires showed that the actions of the project $100 \%$ Recyclable School showed better results than the campaign Stop the Waste.
\end{abstract}

Keywords: Schools. Evaluation of Environmental Education Programs. Solid Waste.

\footnotetext{
${ }^{1}$ Mestre em Ciência e Tecnologia Ambiental pela Universidade Tecnológica Federal do Paraná (UTFPR), Curitiba, Paraná, Brasil

${ }^{2}$ Professora Adjunto da Universidade Tecnológica Federal do Paraná (UTFPR), Professora no Curso de PósGraduação em Ciência e Tecnologia Ambiental e do Mestrado profissional de Formação Científica, Educacional e Tecnológica da UTFPR, Curitiba, Paraná, Brasil.
} 


\section{EVALUACIÓN DE LOS PROGRAMAS DE EDUCACIÓN AMBIENTAL PARA LA GESTIÓN DE RESIDUOS SÓLIDOS EN LAS ESCUELAS MUNICIPALES DE PINHAIS/PR}

\section{Resumen}

Este estudio tiene como objetivo evaluar los programas de educación ambiental para la gestión de residuos sólidos en dos escuelas públicas en Pinhais/PR. Los programas son dos: la campaña Parar el despilfarro y el proyecto Escuela 100\% Reciclable que hasta entonces no habían sido sometidos a ningún tipo de evaluación para determinar el alcance de sus objetivos. El estudio de caso se desarrolló en las escuelas municipales Aroldo de Freitas y 31 de Marzo, con los alumnos de $\operatorname{los} 4^{\circ}$ y $5^{\circ}$ años de la escuela primaria. El método cuantitativo y cualitativo fueron utilizados para analizar los resultados obtenidos mediante la aplicación de cuestionarios para evaluar e investigar el conocimiento de los sujetos de investigación con respecto a estos programas. Las respuestas de la encuesta se agruparon en categorías y, por lo tanto, podrían traducirse en datos de porcentaje. Los resultados mostraron que las acciones del Proyecto de la Escuela $100 \%$ reciclable presentan mejores resultados en relación con la campaña Parar el despilfarro.

Palabras-clave: Escuelas. Evaluación de programas de Educación Ambiental. Residuos sólidos

\section{Introdução}

A crescente urbanização, o aumento da população e o consumo acelerado dos recursos naturais resultam no aumento da produção de resíduos sólidos e impactos na natureza. Tais fatores também estão relacionados aos aspectos sociais, econômicos e administrativos que podem estar envolvidos na questão, seja de maneira positiva ou negativa (SIQUEIRA; MORAES, 2009). Para Mucelin e Bellini (2008), os danos ambientais relacionados aos resíduos se apresentam de forma significativa e desafiadora, pelo fato de acarretarem alterações ambientais físicas e biológicas ao longo do tempo, modificando e comprometendo os ecossistemas.

A Região Metropolitana de Curitiba (RMC) vem sendo impactada pelas limitações da disponibilidade hídrica, tanto em quantidade como em qualidade, para seu abastecimento. $\mathrm{O}$ aumento populacional e a ocupação irregular e desordenada da RMC, em decorrência da falta de fiscalização e descumprimento à regulamentação de uso e ocupação do solo, gerou problemas, principalmente às margens do Rio Atuba e do Rio Palmital, que passaram a receber cargas de esgoto sanitário, predominantemente doméstico e resíduos sólidos, ocasionando forte impacto ambiental (GARCIAS; SANCHES, 2009).

Em virtude da degradação da qualidade de suas águas, os rios em questão perderam a caracterização de mananciais e foram desconsiderados para o abastecimento público (ANDREOLI, 2003; CHEPAK, 2008).

Na visão de Quintas (2004), a gestão ambiental em si faz parte do processo educativo, e suas ações estão comprometidas tanto com o âmbito formal quanto o não formal da Educação Ambiental (EA). Ainda, segundo o mesmo autor, o objetivo da gestão também seria o de fomentar condições para formação e obtenção de conhecimentos para o público alvo ao qual se destina. Além disso, a gestão ambiental pode oportunizar o desenvolvimento de condutas com vistas à conscientização e participação individual e coletiva, na forma de gerir o uso dos recursos naturais, e no processo de tomada de decisões que possam vir a afetar, direta e indiretamente, a qualidade dos meios físico-natural e sociocultural.

Para que a gestão de resíduos sólidos nas escolas possa ser incorporada como processo educativo, faz-se necessário avaliar as ações relacionadas para verificar a efetividade das 
mesmas. Dessa maneira, para que programas de EA possam ter continuidade e sejam incorporados como parte da gestão ambiental nas escolas, faz-se necessário avaliar o processo de sensibilização e resultados efetivos dos mesmos. Besen e Ribeiro (2008) afirmam que a avaliação de programas pode tornar-se instrumento relevante para proposição de metas de gestão, ampliando sua extensão, continuidade e fortalecimento.

Nesse sentido, em decorrência da poluição da bacia hidrográfica do rio Atuba e demais rios de Pinhais, que ocorre principalmente pelo lançamento clandestino de lixo nos rios, entende-se que a EA deva ser voltada para auxílio na preservação dos recursos hídricos do município, e o tema a ser abordado com maior ênfase é a gestão de resíduos. Desse modo, esta pesquisa buscou avaliar os Programas de EA denominados campanha Acabe com o Desperdício e projeto Escola $100 \%$ Reciclável, desenvolvidos pela Prefeitura de Pinhais, voltados para sensibilizar e conscientizar a comunidade escolar, assim como inserir a gestão de resíduos sólidos nas escolas. A avaliação da eficácia desses programas como processo educativo não havia sido realizada até então. O público alvo desta pesquisa aqui apresentada foram alunos do $4^{\circ}$ e $5^{\circ}$ anos do Ensino Fundamental das Escolas Aroldo de Freitas (Escola A) e 31 de Março (Escola B), localizadas na bacia do rio Atuba.

\section{Programas de Educação Ambiental voltados para gestão de resíduos sólidos no município de Pinhais/PR}

\subsection{Campanha Acabe com o Desperdício}

A campanha Acabe com o Desperdício foi lançada em 2009, pela Prefeitura de Pinhais/PR, visando a redução e a correta separação dos resíduos sólidos gerados no município. O Departamento de Meio Ambiente, da Secretaria de Desenvolvimento Sustentável em parceria com a Secretaria de Educação capacitou educadores e professores da rede municipal de ensino para atuarem nessa campanha (PINHAIS, 2010).

A campanha, que se estendeu para o ano de 2010, consistiu em ampla divulgação para a população a respeito da necessidade da separação correta do lixo, por meio de materiais gráficos, cartazes em locais públicos e em ônibus, outdoors, informativos, anúncios em jornais, adesivos para as lixeiras, web banner no site da prefeitura e outras ações de EA com alunos da rede municipal de ensino. Foram entregues nas escolas coletores com cores diferenciadas para os tipos de resíduos, cartilhas indicando como deveria ser a separação dos resíduos; os professores inseriram o tema nas atividades curriculares, e as feiras do conhecimento desenvolvidas nas escolas e abertas à visitação da comunidade apresentaram o tema da coleta seletiva.

Cabe destacar que, em órgãos públicos, inclusive em escolas municipais, houve disponibilização de lixeiras com as cores correspondentes aos materiais orgânicos (marrom), recicláveis (verde) e rejeitos (cinza) (PINHAIS, 2010). Aponta-se que os rejeitos são resíduos sólidos que, depois de esgotadas todas as possibilidades de tratamento e recuperação por processos tecnológicos disponíveis e economicamente viáveis, não apresentam outra possibilidade que não a disposição final ambientalmente adequada, que é o aterro sanitário (BRASIL, 2010).

De acordo com o diagnóstico realizado pela Secretaria de Desenvolvimento Sustentável, a campanha teve resultados significativos para o município, com aumento de $30 \%$ na separação dos resíduos (PINHAIS, 2010). Porém, não foram encontrados pelas pesquisadoras registros indicando algum tipo de avaliação nas repartições públicas e escolas, que corroborassem tais resultados, demonstrando a eficácia da campanha como ação de EA para instrução da comunidade, assim como de gestão ambiental nas escolas. 


\subsection{Projeto Escola 100\% Reciclável}

Em 2014, foi desenvolvido o projeto Escola 100\% Reciclável, realizado em parceria com as Secretarias de Meio Ambiente e de Educação do município de Pinhais/PR. Nessa campanha, foram envolvidas diversas ações como compostagem, reciclagem, conscientização quanto ao desperdício de alimentos e limpeza e conservação das escolas municipais. O projeto piloto teve seu início no mesmo ano, no Centro de Atenção Integral à Criança e Adolescente (CAIC) Marcelino Champagnat. Dentro da comunidade escolar do complexo CAIC estão a Escola Municipal Antônio Andrade, o Centro Municipal de Atendimento Educacional Especializado às Deficiências Sensoriais Helen Keller e os Centros Municipais de Educação Infantil Marcelino Champagnat e Pequeno Príncipe (PINHAIS, 2014). O projeto teve como objetivo a capacitação de profissionais que atuam nas unidades de ensino, como diretores, professores e funcionários administrativos, da cozinha e da limpeza, bem como a sensibilização dos alunos envolvendo os temas citados.

Na Escola Aroldo de Freitas (A) a intervenção ocorreu no dia 10 de outubro de 2014. $\mathrm{Na}$ Escola 31 de Março (B) a intervenção de EA do projeto Escola 100\% Reciclável se deu nos dias 03 e 06 de outubro de 2014. A intervenção se deu com técnicos da Secretaria de Meio Ambiente e Educação da Prefeitura de Pinhais, e foi aplicada em todas as turmas de $4^{\circ}$ e $5^{\circ}$ anos. A primeira ação se deu por meio de palestra, utilizando-se equipamento de multimídia datashow.

Foi realizada a apresentação e explicação sobre a diferença entre os resíduos orgânicos e recicláveis, importância da separação no ambiente escolar e em casa, coleta seletiva e destinação correta. Também, foi realizada dinâmica de grupo, de modo que os alunos pudessem lançar e acertar as embalagens apresentadas como resíduos sólidos nas duas lixeiras, sendo uma para resíduos orgânico e outra para resíduos recicláveis.

Nesse caso, os resíduos recicláveis também consideravam toda embalagem e material seco, mesmo que alguns não tivessem potencial de reciclagem, ou seja, inclusive os rejeitos eram classificados como recicláveis. O resíduo orgânico seria o material úmido, e não deveria conter embalagens, pois a separação prevista pelo projeto tinha como objetivo utilizar o resíduo orgânico no processo de compostagem e, para tal, o mesmo não poderia estar contaminado com outros resíduos. Além disso, foi feita implantação de duas lixeiras nas salas de aula, sendo uma para resíduo orgânico e outra para resíduo reciclável. Esse projeto não previa a separação de rejeitos, como foi feito na campanha Acabe com o Desperdício.

\section{A importância da avaliação de projetos de Educação Ambiental}

Além de tratar a EA de maneira ampla, a Política Nacional de EA (PNEA), instituída pela Lei $n^{\circ} 9.795 / 99$, aponta a avaliação como preceito e instaura a constituição de políticas públicas para EA baseada em permanente avaliação crítica e construtiva do processo educativo (LOUREIRO, 2011).

Entre as linhas e ações estratégicas do Programa Nacional de EA (ProNEA), o monitoramento e avaliação de políticas, programas e projetos de EA são destacados como necessários, e também são incentivados o desenvolvimento de indicadores e diagnósticos socioambientais (MMA, 2005). As Diretrizes Curriculares Nacionais para a EA destacam que a formulação, execução e avaliação de projetos institucionais e pedagógicos são essenciais para a concepção e integração da EA, de modo a superar a mera distribuição do tema em face dos demais componentes (BRASIL, 2012).

No entanto, na visão de Ferreira (1997), a literatura disponível a respeito de metodologias bem-sucedidas, e objeções experimentadas em programas educativos ambientais, não apresenta a avaliação dos mesmos, no sentido de não permitir a compreensão de quais 
indicadores de avaliação foram utilizados. A carência de mecanismos adequados de avaliação, é vista como um dos principais gargalos ao processo de continuidade da EA (PLACEA, 2003), tanto no âmbito formal como no não formal, pois não consegue informar as lacunas ou avanços que o projeto apresentou, possibilitando as melhorias que poderiam ser desenvolvidas na continuidade do mesmo.

Os autores Tomazello e Ferreira (2001) relatam que diversos estudiosos da área manifestam a dificuldade em avaliar e analisar a eficiência e os resultados de projetos de EA, em virtude da abrangência dos temas e dos objetivos. Essa falta de avaliação dos resultados contribui, de maneira significativa, para o desabono e descrédito dos projetos (MATTOS; LOUREIRO, 2011).

Nesse contexto, cabe destacar a execução e avaliação do projeto de EA denominado Vida à Água, o qual foi desenvolvido mediante cenário da poluição dos rios Atuba e Palmital, situados na RMC, município de Pinhais/PR. O Departamento de Química e Biologia/ DAQBI da Universidade Tecnológica Federal do Paraná - UTFPR Campus Curitiba, criou e executou o projeto cuja área de atuação foi definida como sendo a bacia do rio Atuba e a bacia do rio Palmital, porção das respectivas bacias inseridas no município de Pinhais (SÁ, 2013).

Devido à grande importância dos seus mananciais para o abastecimento de Curitiba $\mathrm{e}$ Região Metropolitana, Pinhais foi escolhida para que as ações do projeto fossem realizadas nas escolas municipais Felipe Zeni e Aroldo de Freitas, atendendo 37 professores e 900 alunos, visando sensibilizá-los para as questões ambientais. O projeto foi patrocinado pela Petrobras (Programa Petrobras Ambiental) e as atividades foram iniciadas em 2010 (SÁ, 2013).

Com a finalidade de sensibilizar, empregar e apoiar a prática da gestão ambiental descentralizada, o projeto teve por objetivo propor tecnologia alternativa para saneamento através da construção de Estações de Tratamento de Esgotos (ETEs) por zona de raízes. Além disso, professores em horários de permanência participaram de diversas oficinas de sensibilização, ofertadas pelo projeto da UTFPR, com os temas: recursos hídricos, com destaque para as bacias hidrográficas dos rios Palmital e Atuba; saneamento; mata ciliar; e resíduos sólidos, o último envolvendo questões sobre compostagem, coleta seletiva, separação adequada dos resíduos recicláveis e aterro sanitário (SÁ, 2013).

O projeto, voltado à gestão de bacias hidrográficas, passou por detalhado processo de análise e avaliação. A metodologia adotada foram os mapas mentais e aplicação de questionários com alunos e entrevistas com docentes de duas escolas participantes do projeto. A avaliação permitiu constatar sua efetividade no aprendizado de novos conhecimentos, sensibilização e mudança de atitudes em relação às problemáticas ambientais junto à comunidade escolar (SÁ, 2013).

Assim como o projeto Vida à Água, muitos programas de EA estão sendo implementados, principalmente por instituições de ensino, organizações não governamentais e órgãos governamentais vinculados às áreas socioambiental e educacional, visando à melhoria da qualidade de vida das comunidades. Agências internacionais de financiamento vêm exigindo a inclusão da EA nos programas governamentais. $O$ fato tem causado demanda de profissionais capacitados na área de EA, e incitado deliberações sobre a aplicação de metodologias. A avaliação de programas de EA se faz importante sob a ótica da socialização dos seus resultados, os quais poderão servir como parâmetros para outras atividades semelhantes (FERREIRA, 1997).

Como o projeto Vida à Água desenvolveu suas atividades na escola Aroldo de Freitas, em Pinhais, que também participou da campanha Acabe com o Desperdício e o projeto Escola $100 \%$ Reciclável, percebeu-se a possibilidade de avaliar se professores e alunos apresentariam algum diferencial na avaliação a ser realizada para as campanhas específicas voltadas para a gestão de resíduos. O projeto Vida à Água já havia desenvolvido atividades lúdicas que tinham como tema gerador o tema da Conservação dos recursos hídricos e a coleta seletiva. 


\section{Metodologia}

Com base no objetivo desta pesquisa, a mesma é classificada como empírica, das ciências sociais e do tipo exploratória. Segundo Gil (2008), a finalidade esse tipo de pesquisa exploratória é desenvolver, esclarecer e modificar conceitos e ideias, com o objetivo de formular problemas mais precisos ou hipóteses pesquisáveis para estudos posteriores.

O estudo de caso foi desenvolvido nas Escolas Municipais Aroldo de Freitas (participante do projeto Vida à Água), denominada na pesquisa como A, e 31 de Março (não participante do projeto Vida à Água), denominada como $B$, ambas localizadas no município de Pinhais/PR. As duas escolas participaram tanto da campanha Acabe com o Desperdício e o projeto Escola $100 \%$ Reciclável.

Os métodos utilizados neste trabalho foram pesquisa qualitativa e quantitativa. Gressler (2003) afirma que a pesquisa quantitativa é caracterizada pela formulação de hipóteses, definições operacionais das variáveis, quantificação nas modalidades de coleta de dados e informações, utilização de tratamentos estatísticos. Por meio da análise estatística, estima-se um resultado médio das variáveis, de modo a classificá-las e analisá-las. Um número alto de indivíduos se faz necessário para que seja possível a realização das análises estatísticas (MAHONEY; GOERTZ, 2006).

Diferentemente da abordagem quantitativa, a pesquisa qualitativa não emprega instrumentos estatísticos como base no processo de análise. É frequentemente utilizada quando se deseja retratar a magnitude de um determinado problema, não implicando em manipulação de variáveis e estudos experimentais. A análise qualitativa permite avaliar os fenômenos por meio de uma visão holística, de modo a considerar todos os componentes de uma situação nas suas interações, assim como as influências recíprocas das mesmas (GRESSLER, 2003).

O questionário aplicado por meio do método Survey, composto por perguntas abertas e fechadas, foi utilizado como instrumento de pesquisa. Diante do tema central da pesquisa, foram desenvolvidos dois questionários. O primeiro questionário (1), apresentou onze perguntas, foi direcionado aos alunos, no qual buscou-se avaliar o conhecimento sobre a campanha Acabe com o Desperdício, assim como a compreensão sobre o conceito de resíduos orgânicos, recicláveis e rejeitos. O mesmo foi aplicado nas Escolas Aroldo de Freitas e 31 de Março, nos dias 24 e 25 de abril de 2014, respectivamente.

O segundo questionário (2), apresentou dez perguntas, também foi direcionado aos alunos, no entanto avaliou-se o conhecimento sobre o projeto Escola 100\% Reciclável desenvolvido pela Prefeitura de Pinhais. Foram envolvidas questões sobre resíduos orgânicos e recicláveis. A questão dos rejeitos foi excluída pelo fato de o projeto não abranger o termo. $\mathrm{O}$ mesmo foi aplicado após intervenção de EA do projeto Escola 100\% Reciclável, no dia 10 de outubro de 2014, na Escola Aroldo de Freitas, e nos dias 03 e 06 de outubro de 2014, na Escola 31 de Março.

No Quadro 1 são apresentadas as informações sobre o objetivo de cada questionário, em quais escolas foi aplicado o questionário, descrição dos envolvidos na pesquisa. 


\begin{tabular}{|c|c|c|c|}
\hline $\begin{array}{l}\text { Questionári } \\
\text { o }\end{array}$ & Objetivo & $\begin{array}{l}\text { Participante } \\
\text { S }\end{array}$ & $\begin{array}{l}\mathrm{N}^{\mathbf{0}} \text { de indivíduos } \\
\text { participantes }\end{array}$ \\
\hline \multirow[b]{2}{*}{1} & \multirow{2}{*}{$\begin{array}{l}\text { Avaliar } \quad \text { o } \\
\text { conhecimento } \\
\text { sobre a campanha } \\
\text { Acabe com o } \\
\text { Desperdicio e o } \\
\text { entendimento } \\
\text { sobre resíduos } \\
\text { orgânicos, } \\
\text { recicláveis } \\
\text { rejeitos. }\end{array}$} & Escola A & $\begin{array}{l}37 \\
\text { alunos }\end{array}$ \\
\hline & & Escola B & $\begin{array}{l}19 \\
\text { alunos }\end{array}$ \\
\hline \multicolumn{4}{|l|}{ Total } \\
\hline \multirow[b]{2}{*}{2} & \multirow{2}{*}{$\begin{array}{l}\text { Avaliar } \\
\text { entendimento } \\
\text { sobre o projeto } \\
\text { Escola } 100 \% \\
\text { Reciclável e o } \\
\text { entendimento } \\
\text { sobre resíduos } \\
\text { orgânicos, } \\
\text { recicláveis. }\end{array}$} & Escola A & $\begin{array}{l}92 \\
\text { alunos }\end{array}$ \\
\hline & & Escola B & $\begin{array}{l}55 \\
\text { alunos }\end{array}$ \\
\hline \multicolumn{3}{|l|}{ Total } & 147 \\
\hline
\end{tabular}

Quadro 1 - Objetivos dos questionários, escolas e número de participantes da pesquisa Fonte: As autoras.

$\mathrm{Na}$ Escola A houve participação de duas turmas do $4^{\circ}$ ano e três turmas do $5^{\circ}$ ano. $\mathrm{Na}$ Escola B houve participação de uma turma do $4^{\circ}$ ano e duas turmas do $5^{\circ}$ ano. Para o questionário 1, o número de participantes totalizou 56 alunos. No questionário 2 participaram 147 alunos. Ainda que o primeiro questionário tenha sido focado na campanha Acabe com o Desperdício e o segundo no projeto Escola 100\% Reciclável, basicamente, as perguntas de ambos permaneceram semelhantes, o que possibilitou a comparação dos resultados obtidos.

Após aplicação dos questionários, todas as respostas foram repassadas em planilhas do Microsoft Office Excel 2007, sem qualquer categorização específica. Devido à grande diversidade de respostas dos questionários, e com base na metodologia proposta por Ghiglione e Matalon (1993) e Gil (2008), as mesmas foram agrupadas em categorias, atendendo ao objetivo específico de cada pergunta. Para fins de análise das variáveis obtidas, os resultados foram calculados em percentuais.

\section{Resultados e discussão}

Os questionários qualiquantitativos, com perguntas abertas e fechadas, aplicados junto aos sujeitos desta pesquisa, possibilitaram quantificar a compreensão dos alunos do $4^{\circ}$ e $5^{\circ}$ anos do ensino fundamental das Escolas A e B, de modo que foi possível avaliar a percepção sobre a campanha Acabe com o Desperdício e sobre o projeto Escola 100\% Reciclável, que envolvem o tema resíduos sólidos. 
Durante a aplicação e análise dos questionários, observou-se que muitos alunos do $4^{\circ} \mathrm{e}$ $5^{\circ}$ anos possuíam dificuldade para ler e escrever com letra legível. Alguns alunos precisaram de ajuda para o preenchimento dos questionários, pois não sabiam ler nem escrever. Segundo Silva et al. (2013), o nível de leitura e escrita apresentado por alunos vem sendo alvo de preocupação de educadores de todo o Brasil, principalmente dos professores de Língua Portuguesa. $\mathrm{O}$ fato é atribuído às dificuldades apresentadas por esses alunos, tais como a falha na compreensão de material escrito, erros de ortografia e sintaxe, problemas na estruturação, organização e pontuação das frases e parágrafos. Tais dificuldades são acentuadas pela falta de interesse à leitura, que pode ocorrer em virtude da falta de incentivo à leitura e à escrita, e ainda pela ausência de contato com livros, revistas e jornais.

Por meio do questionário 1 , foi possível verificar que o conhecimento sobre a campanha Acabe com o Desperdício foi muito baixo, sendo de 2,7\% na Escola A e 10,5\% na Escola B. Como essa campanha disponibilizou três lixeiras e cores, e a escola estava trabalhando com o projeto Vida à Água apenas com duas cores, a falta do entendimento da cor cinza gerou o resultado tão baixo para o entendimento dessa campanha. A escola $\mathrm{B}$, que ainda possuía lixeiras na cor cinza, obteve uma compreensão melhor na diferenciação das cores e lixeiras voltadas para essa campanha. Mas, de qualquer forma, os resultados se mostraram baixos para o entendimento voltado a essa campanha. Após a intervenção de algumas ações voltadas ao tema, o entendimento desse mesmo público alcançou o nível de 95,7\% para Escola A e $89 \%$ para a Escola B, demonstrando a importância de se manter as ações e atividades de EA de forma constante, para a obtenção de resultados positivos para campanhas.

Para o presente estudo, parece evidente que a intervenção do projeto Escola $100 \%$ Reciclável, que é aplicado em período muito próximo ao período de avaliação, permitiu um resultado mais favorável em relação à percepção da maioria dos alunos envolvidos, com a correta segregação dos resíduos. A campanha Acabe com o Desperdício já não vinha sendo apresentada para o público escolar por quase um ano. Os resultados obtidos pela avaliação após as atividades do projeto indicam aumento na compreensão dos conceitos para $93 \%$ dos participantes da Escola A, e 78,6\% na Escola B.

Ruffino (2001) destaca que, quando considerada a participação consciente dos sujeitos em programa de coleta seletiva, o mesmo pode ser orientado e vinculado a estruturas sólidas e portadoras de ferramentas pedagógicas que auxiliem na manutenção do processo educativo, e de integração a ser desenvolvido na comunidade. As unidades de ensino parecem agregar plenas condições para efetivação da Política Nacional de EA, bem como, para favorecer o desenvolvimento da EA não-formal juntamente com a comunidade local.

Para a campanha Acabe com o Desperdício fez-se a verificação das cores das lixeiras que se encontravam nas escolas avaliadas. Como as duas campanhas avaliadas possuem cores e números diferentes para cada lixeira, tornou-se necessário verificar qual estrutura de coleta estava sendo disponibilizada nas escolas. Na campanha Acabe com o Desperdício eram utilizadas lixeiras para os resíduos orgânicos com a cor marrom, para reciclável a cor verde, e para rejeito a cor cinza. No período pós-intervenção foram consideradas somente lixeiras para orgânico e reciclável, porém sem identificação por cores, conforme ações do projeto Escola $100 \%$ Reciclável.

O reconhecimento correto das lixeiras foi maior na Escola A $(13,5 \%)$ e nulo na Escola B. A maioria dos alunos da Escola $\mathrm{A}$, associaram as cores das lixeiras às cores do padrão da Resolução do CONAMA No 275 e ABNT (NBR 15911). Esta associação ocorreu de maneira incorreta na maioria das respostas. Segundo descrito na resolução e na norma citadas, as lixeiras são de plástico e coloridas, sendo: azul para papel, verde para vidro, vermelho para plástico, amarelo para metal, marrom para orgânico, preto para madeira, laranja para resíduos perigosos, roxo para resíduos radioativos, branco para resíduos ambulatoriais e de serviços de saúde e cinza para resíduo geral não reciclável (BRASIL, 2001; ABNT, 2011). 
Esse resultado demonstra que a estrutura para a coleta seletiva não está definida no processo de gestão, tanto da escola, como do município. Foram encontradas lixeiras coloridas conforme a Resolução CONAMA N ${ }^{\circ} 275$, lixeiras das cores marrom, verde e cinza, e, ainda, lixeiras fixas, nos pátios, que estavam pintadas de verde, mas tinham adesivos que indicavam qual seria para resíduos recicláveis e qual para orgânicos. Essa oferta de lixeiras com padrões e cores diferenciados causa confusão no entendimento e na percepção dos alunos quanto a forma correta de segregação dos resíduos na escola.

A confusão gerada pela disponibilização de diferentes lixeiras ficou evidenciada nos resultados obtidos pelo questionário voltado ao projeto Escola $100 \%$ Reciclável, o qual teve suas ações desenvolvidas próximo ao período da aplicação do questionário. Como resultado do reconhecimento das lixeiras voltadas ao projeto, $76 \%$ participantes da Escola A acertaram as cores, e apenas 32,7\% participantes da Escola B obtiveram acerto nas respostas. Isto indica que, de alguma forma, a intervenção do projeto não foi suficiente para gerar o conhecimento satisfatório, e que a oferta de diferentes lixeiras, sem apresentar uma uniformidade nos padrões de cores, é prejudicial para a compreensão dos alunos. Diante disso, os resultados apontam para a necessidade de ações contínuas de EA junto ao corpo discente e a definição da estrutura para a coleta seletiva como sendo um elemento chave para a consolidação dos conceitos apresentados pelos projetos.

O resultado obtido na Escola A, apresentando melhores resultados no entendimento das cores, também pode estar associado ao fato dessa escola ter tido uma sequência de atividades mais intensas com o projeto Vida à Água. Esse projeto desenvolveu, ao longo de quatro anos, ações e atividades voltadas ao tema dos resíduos recicláveis e orgânicos, associados à conservação dos Recursos Hídricos. Nesse sentido, Silva, Oliveira e Torres (2014), ressaltam que o grande desafio para a educação é garantir aprendizagem expressiva, de modo a criar nos educandos conhecimentos, hábitos e atitudes ambientalmente corretos, por meio de práticas construídas no cotidiano do ambiente escolar.

Quanto ao nível de reconhecimento das categorias orgânico e reciclável, o mesmo ficou melhor entendido no período de intervenção do projeto Escola 100\% Reciclável, tanto na Escola A quanto na Escola B.

A compreensão e diferenciação entre um resíduo e outro são as primeiras etapas para se garantir a separação adequada desses resíduos. No entanto, é preciso que os alunos sejam instruídos e constantemente motivados em favor da mudança de atitudes em relação aos seus papéis na gestão de resíduos sólidos, não só no ambiente escolar como em seus lares. Muller (2005) afirma que a motivação é capaz de realizar mudanças no comportamento das pessoas. Nesse contexto, o estímulo para uma conduta motivada pode despertar os indivíduos para as ações com entusiasmo e persistência, tanto sob a luz pontual da coleta seletiva, quanto da preservação do Meio Ambiente.

Quanto à questão dos rejeitos, cerca de $84 \%$ dos alunos de ambas as escolas não reconheceram o conceito para rejeitos, sendo que apenas 2,7\% da Escola A e 5,3\% da Escola $\mathrm{B}$ identificaram corretamente os mesmos. Alguns alunos associaram os rejeitos às coisas velhas e que não podem ser reutilizadas, restos de comida e lixo radioativo.

Quanto ao conceito para o termo destinação, 72,9\% dos alunos da Escola A e 94,7\% da Escola B informaram que os rejeitos são destinados ao aterro sanitário e/ou lixão, não conhecem portanto, a diferença entre os termos.

Quanto à identificação do resíduo reciclável, a identificação correta foi de 45,7\% na Escola A e 49\% na Escola B. A identificação correta caracterizou a descrição de resíduo reciclável como sendo: papel, plástico, vidro, metal e embalagem longa vida. Alguns alunos associaram restos de comida ao resíduo reciclável, o que de fato não deixaria de estar correto, partindo do princípio que restos de comida podem ser reaproveitados na compostagem. No entanto, para fins de análise, restos de comida, não foi considerado como resposta correta nessa 
questão, devido ao fato de haver o entendimento do projeto Escola $100 \%$ Reciclável que a destinação dos orgânicos seria para a compostagem e, no contexto do referido projeto, os orgânicos não seriam conceituados como recicláveis, pois apenas os materiais secos são tidos como recicláveis.

Deve-se ressaltar que esse tipo de caracterização foi definido pelo Escola $100 \%$ Reciclável, em contraposição à definição legal proposta pela Lei 12305/ 2010 (BRASIL, 2010, p.1), que inclui os orgânicos no Art.3, item XIV, considerando passíveis de reciclagem: "processo de transformação dos resíduos sólidos que envolve alteração de suas propriedades físicas, físico-químicas ou biológicas, com vistas à transformação em insumos ou novos produtos, observadas as condições e os padrões estabelecidos pelos órgãos competentes do Sisnama e, se couber, do SNVS e do Suasa", ou seja, pela Lei 12305/2010, os orgânicos podem ser considerados recicláveis.

Observou-se, na análise geral, que a Escola A demonstrou percentual maior relativo à percepção correta dos conceitos sobre os resíduos sólidos. Conforme já mencionado, esse fato pode estar relacionado ao desenvolvimento das ações anteriores do projeto Vida à Água, e uma melhor estruturação das lixeiras dispostas nessa escola, definindo melhor o padrão de cores, sendo somente duas, e eventualmente uma séria de lixeiras coloridas que estão sendo utilizadas pela cozinha da escola. Segundo Sá (2013), dentre as ações do projeto Vida à Água, a questão sobre resíduos recicláveis foi tratada durante atividades lúdicas junto aos alunos da pré-escola ao $5^{\circ}$ ano dessa escola. De acordo com Silva e Leite (2008), estratégias metodológicas baseadas na ludicidade são capazes de promover a sensibilização dos indivíduos. Dentre essas estratégias destacam-se: dinâmicas de grupo; aulas de campo; passeio em parques; oficinas com material de sucata; reciclagem de papel; gincana; uso de vídeo; festival de arte e cultura; utilização de músicas populares e paródias; músicas com gestos; cantigas de roda; histórias infantis, histórias em quadrinhos; charges; mímicas; danças; ginásticas; relaxamento; palestra; teatro; produção de textos, desenhos e pinturas.

Nesse sentido, tais atividades podem e devem fazer parte do dia-a-dia de docentes e alunos, para que a questão dos resíduos sólidos seja constantemente abordada e colocada em prática.

Ainda que somente a Escola A tenha passado pelas ações do projeto Vida à Água, nas quais foram abordadas as questões sobre compostagem, tanto os alunos da Escola A quanto da Escola B associaram a destinação do lixo orgânico ao reaproveitamento para compostagem e produção de adubo, demonstrando que o tema, de alguma forma, está no consciente dos alunos, e poderia ser melhor aproveitado em ações práticas na escola.

Segundo dados da Prefeitura de Pinhais (2014), a Associação dos Recicladores de Pinhais (AREPI) se tornou parceira do projeto Escola 100\% Reciclável. Nesse sentido, seria importante a mobilização e realização de trabalhos conjuntos entre a comunidade escolar e a AREPI, visando o fortalecimento dessa aliança e a compreensão e sensibilização dos alunos quanto à destinação dos resíduos sólidos, bem como sobre a realidade dos catadores da Associação. No entanto, é necessário adequar a linguagem do projeto para que a sensibilização ocorra de fato, pois a avaliação demonstrou que houve confusão no entendimento dos conceitos, principalmente no que se refere a destinação final, como Aterro Sanitário, assim como na compreensão das cores das lixeiras.

A promoção de visitas dos alunos à AREPI pode vir a ser importante atividade de campo interdisciplinar, de modo a sensibilizar não só alunos, mas todo o corpo docente para a prática da cidadania, da EA e da gestão dos RS no ambiente escolar e, consequentemente, em suas residências. Couto (2012) destaca o aprendizado social que ocorre no interior das cooperativas de catadores. Em seu trabalho, a autora pôde constatar que esses indivíduos estabelecem, em seu cotidiano de trabalho, ricas relações de ensino-aprendizagem e de interação social. 
Além disso, é preciso deixar claro a toda comunidade escolar que, embora haja benefícios com a reciclagem dos resíduos sólidos, a mesma não deve ser vista como único recurso na busca pela preservação do meio ambiente. Nesse sentido, Adissi, Pinheiro e Cardoso (2013) recordam que a Política Nacional de Resíduos Sólidos - PNRS, na qual é tratada a adoção de padrões sustentáveis de produção e consumo de bens e serviços, onde a problemática dos Resíduos Sólidos - RS não pode ser tratada somente sob o ponto de vista reducionista.

Os gestores do projeto Escola 100\% Reciclável, bem como os docentes das escolas envolvidas devem trabalhar a questão, norteados pela PNRS, e sob a luz da visão menos reducionista da mudança de hábitos e padrões de consumo, da não geração e redução dos RS.

Os resultados demonstram a importância da presença e manutenção de estruturas adequadas, como composteiras e hortas, para destinação do resíduo orgânico como reaproveitamento. Além disso, comprovam o quanto são necessárias atividades de EA envolvendo alunos nesses espaços. Rodrigues et al. (2013) observaram que as atividades de conscientização ambiental são essenciais, pois é possível repassar, de maneira prática e simples, a relevância da segregação da fração orgânica do resíduo na fonte geradora, bem como o emprego da compostagem no tratamento da mesma.

\section{Conclusões}

O levantamento de dados acerca dos Programas de EA denominados campanha Acabe com o Desperdício e Programa Escola 100\% Reciclável, voltados para gestão de resíduos sólidos em escolas municipais de Pinhais/PR, promoveu a possibilidade da compreensão, por parte das pesquisadoras, de como os alunos percebem e assimilam os conceitos repassados.

Por meio dos questionários aplicados junto aos sujeitos da pesquisa, identificou-se que as ações do projeto Escola $100 \%$ Reciclável apresentaram melhores resultados em relação à campanha Acabe com o Desperdício.

De modo geral, os alunos obtiveram baixo/médio entendimento em relação aos programas citados. Constatou-se que a Escola A, provavelmente em decorrência da participação no projeto Vida à Água, no qual foi trabalhado o tema resíduos sólidos, durante quatro anos, apresentou melhores resultados em relação à Escola B, nos períodos pré e pós-intervenção de EA. Esse fato demonstra o quanto a capacitação e a informação continuada são necessárias, mesmo para temas básicos como coleta seletiva.

Concluiu-se que a implantação das três lixeiras (orgânico, reciclável e rejeito) da campanha Acabe com o Desperdício não foi eficiente, uma vez que, as ações da campanha não demonstraram efeito sobre a percepção dos alunos para a coleta seletiva orientada para orgânicos, recicláveis e rejeitos.

O projeto Escola 100\% Reciclável contribuiu de maneira mais positiva nos resultados, com o aumento do entendimento dos alunos participantes da pesquisa em relação ao tema resíduos sólidos e suas correlações, mas esse projeto teve ações recentes implementadas nas escolas.

A realização desta pesquisa foi muito importante para a avaliação da campanha Acabe com o Desperdício e do projeto Escola 100\% Reciclável, visto que foi possível comparar os dois programas, bem como identificar o entendimento dos participantes, favorecendo a busca pelo aperfeiçoamento, sucesso e fortalecimento do atual e de futuros projetos. Também, foi possível avaliar a importância da manutenção de atividades e ações voltadas para o tema de forma contínua. O projeto Vida à Água, que manteve atividades lúdicas voltadas ao tema dos resíduos pelo período de quatro anos, foi relevante no sentido de manter o tema ativo na escola A. Os resultados dos questionários indicam que a compreensão da escola A para os conceitos voltados aos resíduos sólidos foi melhor do que na escola B. Portanto, as atividades devem ser 
contínuas, a estrutura para a coleta seletiva deve ser padronizada e a linguagem deve ser adequada para o público alvo.

\section{Referências}

ADISSI, P. J.; PINHEIRO. F. A.; CARDOSO, R. da S. Gestão Ambiental de Unidades Produtivas. Rio de Janeiro, RJ: Elsevier Brasil, 2013.

ANDREOLI, C. V. (Org.) Mananciais de abastecimento: planejamento e gestão. Estudo de caso do Altíssimo Iguaçu. Curitiba: Sanepar; Finep, 2003. p.163.

ASSOCIAÇÃO BRASILEIRA DE NORMAS TÉCNICAS (ABNT). NBR 15911-3:2010: Contentor móvel de plástico. São Paulo:ABNT, 2011.

BESEN, G. R.; RIBEIRO, H. Indicadores de sustentabilidade para programas municipais de coleta seletiva-métodos e técnicas de avaliação. In: WORKSHOP INTERNACIONAL DE PESQUISA EM INDICADORES DE SUSTENTABILIDADE -WIPIS, II. p. 159-174.São Carlos: EESC/USP, 2008.

BRASIL. Ministério do Meio Ambiente. Resolução $n^{o}$ 275, de 25 abril de 2001. Brasília: Conselho Nacional do Meio Ambiente, 2001.

BRASIL. Lei $n^{\circ} 12.305$, de 02 de agosto de 2010. Institui a Política Nacional de Resíduos Sólidos; altera a Lei ${ }^{0}$ 9.605, de 12 de fevereiro de 1998; e dá outras providências. Brasília: Casa Civil, 2010. Disponível em: <http://www.planalto.gov.br/ccivil_03/_ato2007-2010/2010/lei/112305.htm>. Acesso em: 21 set. 2014.

BRASIL. Lei $n^{\circ}$ 9.795, de 27 de abril de 1999. Dispõe sobre a Educação Ambiental, institui a Política Nacional de Educação Ambiental e dá outras providências. Brasília: Casa Civil, 1999. Disponível em: <http://www.planalto.gov.br/ccivil_03/leis/19795.htm>. Acesso em: 27 set. 2012.

CHEPAK, M. F. de A. Atlas Geográfico do município de Pinhais. 2008.

COUTO, G. A. Aprendizagem social e formação humana no trabalho cooperativo de catadores (as) em São Paulo. 2012. 151 f. Dissertação (Mestrado em Educação) - Programa de Pós-Graduação em Educação da Faculdade de Educação da Universidade de São Paulo, São Paulo, 2012.

FERREIRA, M. V. G. de Q. Subsídios Metodológicos para Elaboração e Implementação de Projetos de Educação Ambiental. In: CONGRESSO BRASILEIRO DE ENGENHARIA SANITÁRIA E AMBIENTAL, 19, 1997, Foz do Iguaçu. Anais... Foz do Iguaçu: ABES, 1997.

GARCIAS, C. M.; SANCHES, A. M. Vulnerabilidades socioambientais e as disponibilidades hídricas urbanas: levantamento teórico-conceitual e análise aplicada à região metropolitana de Curitiba - PR. Revista de Pesquisa em Arquitetura e Urbanismo, São Carlos, n. 10, p. 96-149, 2009.

GHIGLIONE, R.; MATALON, B. O Inquérito, Teoria e Prática. Oeiras: Celta, 1993.

GIL, A. C. Métodos e técnicas de pesquisa social. 6 ed. São Paulo: Atlas, 2008.

GRESSLER, L. A. Introdução à pesquisa. São Paulo: Edições Loyola, 2003.

LOUREIRO, C. F. B. Avaliação de processos de Educação Ambiental na Gestão das Águas. In PAULA JR, F. de; MODAELLI, S. (Orgs). Política de águas e Educação Ambiental: processos dialógicos e formativos em planejamento e gestão de recursos hídricos. Brasília: MMA/ Secretaria de Recursos Hídricos e Ambiente Urbano, 2011, p. 51-56. 
MAHONEY, J.; GOERTZ, G. A Tale of Two Cultures: Contrasting Quantitative and Qualitative Research. Political Analysis, Cambridge, v.14, p. 227-249, June. 2006.

MATTOS, L. M. A.; LOUREIRO, C. F. B. Avaliação em educação ambiental: estudo de caso de um projeto em contexto de licenciamento. Pesquisa em Educação Ambiental, Rio Claro, v. 6, n. 2, p. 3343, jul-dez. 2011.

MINISTÉRIO DO MEIO AMBIENTE. Programa Nacional de Educação Ambiental - ProNEA. 3 ed. Brasília: MMA, 2005.

MUCELIN, C. A.; BELLINI, M. Lixo e impactos ambientais perceptíveis no ecossistema urbano. Sociedade \& natureza, Uberlândia, v. 20, n. 1, p. 111-124. 2008.

MULlER, V. L. S. Coleta Seletiva de Lixo em Escolas do Município de Canoas-RS: Análise de um projeto. 2005. 112 f. Dissertação (Mestrado em Ensino de Ciências e Matemática) - Programa de Pós Graduação em Ensino de Ciências e Matemática - Universidade Luterana do Brasil, Canoas-RS, 2005.

PINHAIS. Prefeitura de Pinhais. Campanha contra o desperdício de Pinhais será ampliada em 2010. [Online]. Portal da Prefeitura de Pinhais, 2010. Disponível em: <http://www.pinhais.pr.gov.br News7content1476.shtml>. Acesso em: 9 mai. 2013.

PINHAIS. Prefeitura de Pinhais. Projeto leva conscientização ambiental às unidades de ensino de Pinhais. [Online]. Portal da Prefeitura de Pinhais, 2014. Disponível em: <http://www.pinhais.pr.gov.br/News7content8637.shtml>. Acesso em 14 out. 2014.

PROGRAMA LATINO-AMERICANO E CARIBENHO DE EDUCAÇÃO AMBIENTAL - PLACEA. Proposta do Programa Latino-americano e Caribenho de Educação Ambiental no Marco do Desenvolvimento Sustentável. Resumo Executivo. Brasília: Órgão Gestor da Política Nacional de Educação Ambiental, 2003. Disponível em: <www.reasul.org.br/mambo/files/placea_resexec.pdf>. Acesso em: 11 dez. 2014.

QUINTAS, J. S. Educação no processo de Gestão Ambiental: uma proposta de Educação Ambiental transformadora e emancipatória. In LAYRARGUES, P. P. (Coord.). Identidades da Educação Ambiental Brasileira. Brasília: MMA, 2004.

RODRIGUES, A. et al. Ações de Conscientização Ambiental no Aproveitamento e Transformação dos Resíduos em Escola Estadual. In: SEMINÁRIO DE EXTENSÃO UNIVERSITÁRIA DA REGIÃO SUL, $31^{\circ}$ SEURS, 2013, Florianópolis. Anais... Florianópolis: Universidade Federal de Santa Catarina, 2013. p.01-06. Site.

RUFFINO, P. H. P. Proposta de educação ambiental como instrumento de apoio à implantação e manutenção de um posto de orientação e recebimento de recicláveis secos em uma escola estadual de ensino fundamental. 2001.64 f. Dissertação (Mestrado em Hidráulica e Saneamento) - Escola de Engenharia de São Carlos da Universidade de São Paulo, São Carlos, 2001.

SÁ, P. Z. de. Análise e avaliação do projeto de Educação Ambiental "vida e água" voltado à gestão de bacias hidrográficas (Pinhais-PR). 2013. 142 p. Dissertação (Mestrado em Ciência e Tecnologia Ambiental) - Universidade Tecnológica Federal do Paraná, Programa de Pós-graduação em Ciência e Tecnologia Ambiental, Curitiba, 2013.

SILVA, M. M. P. da; LEITE, V. D. Estratégias para Realização de Educação Ambiental em Escolas do Ensino Fundamental. Educação Ambiental, n.4 p. 133-144, 2008. 
SILVA, A. M. da et al. Escreveu e Leu: as Dificuldades de Leitura e de Produção Textual Apresentadas por Alunos do Ensino Fundamental de Uma Escola da Rede Pública. Cadernos de Pesquisa, São Luís, v. 20, n. 2, p.41-48, maio -ago. 2013.

SILVA, C. O; OLIVEIRA, F. S.; TORRES, M. S. Coleta Seletiva e Reciclagem Como Cultura Ambiental no Contexto Escolar. GEOSABERES-Revista de Estudos Geoeducacionais, Fortaleza, v. 5, n. 09, p.13-25, jan-jun.. 2014.

SIQUEIRA, M. M.; MORAES, M. S. Saúde coletiva, resíduos sólidos urbanos e os catadores de lixo. CienSaudeColet., São José do Rio Preto, v. 14, n. 6, p. 2115-22, dez. 2009.

TOMAZELLO, M. G. C.; FERREIRA, TR das C. Educação ambiental: que critérios adotar para avaliar a adequação pedagógica de seus projetos. Ciência \& Educação, Bauru, v. 7, n. 2, p. 199-207, jun. 2001. 